\title{
Embracing a Philosophy of Lifelong Learning in Higher Education: Starting with Faculty Beliefs about Their Role as Educators
}

\section{Carolin Kreber}

University of Alberta

Recent events on the international political scene point to a need to teach course content and learning skills that focus on issues of equity and diversity, understanding of the local culture and differences among cultures; learning for ethics, citizenship, and democracy, interpersonal skills; and an ability to make informed and responsible value judgments. These, among others, are important aspects of lifelong learning. To embrace a philosophy of lifelong learning in higher education it seems paramount to focus on faculty beliefs about teaching to encourage a critical interrogation of course and program goals. The chapter concludes with several suggestions for the practice of faculty development.

\section{INTRODUCTION}

In this chapter, I will first suggest that there are two different ways of learning about teaching, which, by extension, represent two different approaches to faculty development. Subsequently, I will review some literature on the meaning of lifelong learning and show how a philosophy of lifelong learning is linked to one's goals and purposes of college and university teaching. Finally, I will highlight the practical implications of what has been suggested for the practice of faculty development. 
When thinking about the type of learning that educational developers may opt to foster among faculty, we can distinguish two different approaches. The first could be seen as being aimed at encouraging faculty to reflect on, and learn about, how to promote certain skills, knowledge, and attitudes in their students. This approach understands learning about teaching as a process that occurs within a given framework of predetermined educational goals and purposes. The goal is to work toward to these given ends, not to question them. The second approach would be aimed at encouraging faculty to reflect on, and learn about, the educational goals themselves. This approach understands learning about teaching as questioning of a given framework of educational goals and purposes and as determining the goals of higher education. Certainly, no one would deny that once educational goals and purposes have been identified and deemed valuable, helping students develop in the direction of these goals becomes paramount. Thus, it would seem that both types of learning about teaching - how to promote certain skills, knowledge, and attitudes in students and identifying meaningful educational goals, are important. While the importance of these two types of learning about teaching have long been recognized-there have always been educational philosophers (asking what and why) and instructional designers (asking how)-their implications for faculty development to date have not been fully realized. In further illustrating the fundamental difference between these two types of learning about teaching, the contributions of German critical social theorist Jürgen Habermas (1971, 1981) and American adult education scholar Jack Mezirow (1991) seem particularly helpful. In briefly summarizing the most significant points of their work, an effort is made to highlight its practical implications.

\section{Different Ways of Learning}

In his classic Knowledge and Human Interests, Habermas (1971) argues that there are three basic human interests: controlling nature, social harmony, and individual growth. Over the course of human evolution, these three interests have given rise to three different kinds of knowledge-the instrumental, the communicative, and the emancipatory. Each kind of knowledge is generated by a certain form of science, together with its corresponding procedures for testing the validity of truth claims-hypothesis testing through the scientific method (empirical-analytical science), reaching understanding through consensus (hermeneutics), and emancipation through critical reflection (critical science), respectively. Though Habermas never discusses learning as such, his theory of knowledge-constitutive interests has provided the basis for Mezirow's (1991, 2001) model of perspective transformation or transformative learning, 
a well-developed construct in adult learning theory (e.g., Cranton, 1994, 1996; Marsick, 1990).

According to Mezirow (1991), the three forms of science Habermas distinguished-the empirical-analytical, the hermeneutic, and the critical-can also be interpreted as three different forms of learning. Learners, like scientists, approach problems in ways that seem most promising to meet desired goals, or interests. If the interest it to establish cause and effect relationships, learning follows the empirical-hypothetical method and it is instrumental in nature. If the interest is to reach greater understanding of what others mean through the written word or dialogue, learning it is communicative. Finally, if the interest is freedom from coercion and distorted ideology, learning becomes emancipatory. As I will show next, it is these three forms of learning that are also present when faculty learn about teaching.

As we saw earlier, faculty may follow the footsteps of the instructional designer and ask, "How can we best promote certain skills, knowledge, and attitudes in my students?" They may also follow the footsteps of the educational philosopher and ask, "Which educational goals are worth our intentional pursuit, and why?"

\section{Instrumental Learning}

When goals and purposes are considered as given, learning is primarily of an instrumental nature. Faculty may wish to learn how to enhance students' reading skills, how to encourage greater motivation, how to increase students' memory of facts and algorithms, how to foster deep-level learning, or how to create more culturally responsive classrooms or appreciation of different lifestyles. In pursuing such endeavors, a faculty member may decide on a particular approach or strategy to be used, develop a set of hypotheses as to what might happen as a result, implement the strategy, collect some data on the way, and interpret these data against the hypotheses. These hypotheses may be derived from personal teaching experience, discussions with colleagues at teaching-related conferences, or knowledge of some of the relevant literature on teaching and learning in higher education. Examples of such hypotheses may include:

- If I provide my students with advance organizers they will achieve better results in summarizing and critiquing the assigned reading materials.

- If I convey the relevance of the material through application to real-life issues students will feel more motivated.

- If I use quizzes students will remember facts and algorithms better. 
- If I base my course on a series of case studies and have students work in small groups to discuss and solve them on their own, they will seek an understanding of important principles and thus engage in deep-level learning.

- If I have course participants share their experiences, allow for discussion, and use examples illustrative of different lifestyles, students will report on this favorably.

Investigations of this kind are very valuable to teachers and students alike as they enhance our understanding of what practices better facilitate student learning. Present initiatives to promote faculty engagement in the scholarship of teaching tend to fall into this domain of learning. The goal is to have faculty consult and contribute to the knowledge base on how to best teach certain subjects by collecting data, interpreting these, and sharing their findings with the larger community. The ultimate purpose of such inquiry, of course, is the enhancement of student learning.

A good example of such an initiative is the Pew National Fellowship Program for Carnegie Scholars (Cambridge, 2000; Hutchings, 1999) offered by the Carnegie Academy for the Scholarship of Teaching and Learning (CASTL). The purpose of the Pew Fellowship program is described as creating

a community of scholars, diverse in all the ways that matter in teaching and learning, whose work will advance the profession of teaching and deepen student learning. The central work of the Carnegie Scholars is to create and disseminate examples of the scholarship of teaching and learning that contribute to thought and practice in the field. (CASTL, n.d.)

Pew scholars are trained in the practice of the scholarship of teaching as they engage in research on teaching and learning within their discipline. Their work is expected to have 1) clear goals, 2) require adequate preparation, 3) make use of appropriate methods, 4) produce significant results, 5) demonstrate effective presentation, and 6 ) involve reflective critique (Glassick, Huber, \& Maeroff, 1997).

It is the first of these criteria that seems particularly important for the present discussion. What does having clear goals mean? I take clear goals to mean a precise articulation of a purpose or problem to be solved. I do not take it to mean, however, a critical interrogation of one's goals. An important question, therefore, is at what point, and by whom, are the goals themselves being examined? I suggest that college and university teaching, or the scholarship 
thereof, can be approached from either a micro or a macro perspective. If we choose to take a micro perspective on (the scholarship of) teaching, we may conclude that goals instructors set for their courses, or certain segments thereof, are determined to a large extent by the field or discipline itself. Few colleagues would deny that each field has its own knowledge base with its own methods of inquiry, and one important goal of instructors, therefore, should be to ensure students are exposed to both the content and ways of thinking aligned with this field. As for one of my own courses on adult developmental/learning theory, for example, one clear goal of mine that likely would remain uncontested, if shared with my peers, is that students understand the major differences between the various developmental/learning theories studied. This goal is deceivingly neutral in a sense that the assumptions, beliefs, and values that underlie it, namely that teaching of content is important, is one that is deeply ingrained in the academy and thus is taken for granted.

However, if we choose to take a macro perspective on (the scholarship of) teaching, the question of what are clear goals reveals itself as being more complex. A macro perspective, the way I define it for the purpose of this chapter, would take into account the broader context in which teaching and learning take place. This context, to a large extent, is defined by the educational philosophical stance of the instructor and the institution. From a macro perspective, the question of clear goals becomes one of desirable goals. Questions that would be asked are, "What, according to the instructor and the institution, is the purpose of higher education, what are the goals, and why are the goals this way?" and only later "How can they best be achieved?" A macro perspective, therefore, includes a critical interrogation of goals. While the Carnegie standards are indeed important-stating one's goals in clear terms and showing evidence of adequate preparation, using appropriate methods, showing significant results, and demonstrating effective presentation and reflective critique on the process and the results-l propose that what has not received sufficient attention to date is reflective critique of the educational goals themselves.

When faculty learn about the meaningfulness, appropriateness, or desirability of educational goals, the learning they are engaged in is not instrumental but communicative in nature (Mezirow, 1991).

\section{Communicative Learning}

Communicative learning is not about testing hypotheses but about reaching greater understanding among individuals. The purpose is "learning to understand what others mean and to make ourselves understood as we attempt to share ideas through speech, the written word" (Mezirow, 1991, p. 75) and in- 
teractions with others. Once a common understanding or consensus has been achieved, on the basis of existing social norms and moral understandings, this is considered valid knowledge. In an article on the scholarship of teaching, Kreber and Cranton (2000) showed that much of faculty learning about teaching falls in the domain of communicative learning. Obviously, when faculty ask, "Which educational goals are worth our intentional pursuit?" this question cannot be answered through instrumental learning but calls for communicative learning. When faculty engaged in communicative learning reach understanding of what are valuable goals, they engage in dialogue framed by their assumptions of what the university as an institution, or perhaps a particular discipline, stands for. Goals are being determined on the basis of consensus. Very important learning can be achieved this way. Such learning is present, for example, when program or course planning committees get together to determine the content of a particular course. These committees are usually formed for large mandatory introductory courses offered in several sections, therefore requiring more than one instructor. Consensus is reached, as we have seen, within a framework of existing assumptions. What is particularly interesting about Habermas's (1971) work is that it suggests these existing assumptions that we hold about university teaching and learning, however, are socially and historically constructed. Consequently, Habermas (1971) encourages people to critically question these long-held assumptions by tracing their origins. When this happens, learning may become emancipatory.

\section{Emancipatory Learning}

When individuals engage in emancipatory learning, the goal is to overcome the limitations of self-knowledge and the social constraints on one's thoughts and actions. Mezirow (1991) suggests that in emancipatory learning "Knowledge is gained through critical self-reflection ... the form of inquiry in critical self-reflection is appraisive rather than prescriptive or designative" (p. 87). One may argue that when faculty critically question why they have certain goals and purposes they engage in emancipatory learning. Such learning may include realizing that educational goals and purposes that seemed very meaningful at some earlier time have outlived their day. It may include realizing that goals have been considered only through the lens of the discipline but not through the lens of the broader learning experience that colleges and universitics should provide.

Let us now explore why attending to educational goals and purposes scems important and why colleges and universities should commit themselves to a philosophy of lifelong learning. 


\section{LIFELONG LEARNING}

Clearly, lifelong learning is not a new concept. So why should lifelong learning be any more significant today than it was when John Dewey discussed learning as a lifelong process in the first quarter of the 20 th century? Is it?

When discussed in the context of higher education, a commitment to lifelong learning is usually seen in educational policies that provide regulations on issues of access, inter- and intra-sector arrangements of credit transfer, prior learning assessment or arrangements for learning at a distance, and continuing education. Basically, these are regulations that permit people to engage in formal learning throughout their adult years. The focus on these discussions is not on what students should learn in order to be successful lifelong learners but on how they could become involved in continuous learning. However, in our rapidly changing world, the development of lifelong learning skills has been recognized as an important goal and responsibility of higher education (Boud, 1997; Candy, 1991; Knapper \& Cropley, 2000). According to this literature, skills and competencies for lifelong learning that should be explicitly taught include communication skills, the ability to think critically, knowledge and skills necessary for working life, and the ability to learn how to learn. In our increasingly complex global society, additional skills and knowledge areas seem important. Recent events on the international political scene call for a much stronger focus in our curricula and programs on issues of equity and diversity; understanding of the local culture and differences between cultures; learning for ethics, citizenship, and democracy; and environmental and health issues. Skills to be learned to function responsibly in such a world would also encompass, I would think, interpersonal skills including empathy and tolerance, integrity, and an ability to make informed and responsible value judgments.

Let us now explore what a few selective scholars of education suggest are important skills and knowledge to be acquired to engage in lifelong learning.

Writing about the necessity to help students self-direct their learning, Bandura (1997) argues that

Good schooling fosters psychosocial growth that contributes to the quality of life beyond the vocational domain. A major goal of formal education should be to equip students with the intellectual tools, efficacy beliefs, and intrinsic interests to educate themselves throughout their lifetime. These personal resources enable individuals to gain new knowledge and cultivate skills either for their own sake or to better their lives. (p. 17) 
Speaking specifically to the role of higher education institutions, Knapper and Cropley (2000) suggest that

Institutions have an important part to play in promoting the development of the personal prerequisites and competencies for lifelong learning. This could be done partly by training people in lifelong learning competencies, and partly by providing them with opportunities to exercise skills they had already acquired. The major purpose would be to equip people in such a way that they wanted to continue learning and believed they could do so. Achieving these goals would require teaching and learning activities that depart from the norms of conventional classrooms. (p. 56)

Knapper and Cropley (2000) also cite Little's (1983) work, who suggested that if Cardinal Newman's beliefs about (liberal) education were translated into statements regarding course content,

he can be seen as advocating that students acquire communication skills, ability in critical thinking, understanding of the local culture and differences between cultures, interpersonal skills (including empathy and tolerance), integrity and an ability to make informed and responsible value judgements, as well as knowledge and skills necessary for working life and the ability to learn how to learn. (p. 57)

Of particular interest are also the areas of knowledge Lengrand (1986), in a document prepared for United Nations Educational, Scientific, and Cultural Organization (UNESCO), identified as minimum content necessary in a system of education that is committed to lifelong learning. These knowledge areas are knowledge of communication, science and technology, the fine arts, ethics and citizenship, time and space, and how to care for one's own body. Environmental education, too, has long been recognized as another important area students in schools, colleges, and universities should be exposed to (Knapper \& Cropley, 2000). Discussing their vision of how universities and colleges could respond to these learning demands, Knapper and Cropley (2000) argue that "the themes in question should run through all courses and programmes, to the maximum extent possible" (p. 58).

And what about educating for citizenship and democracy? Schapiro (1999) raises our awareness of the role contemporary higher education institutions nced to play in educating students about and for democracy-that is 
for liberty, equality, and community. Among the questions education should concern itself with are (Shapiro, 1999, p. 8):

- How can we help students to acquire the skills, attitudes, dispositions, and knowledge they will need in order to be active and responsible democratic citizens?

- How can we create democratic learning communities which recognize and affirm the diversity of all our members?

- How can we affirm and develop each student's individual and particular identity while also helping each of them to develop a commitment to a common good?

- How can we help students to work for social, political, and environmental reconstruction?

- How can we affirm new epistemologies and new ways of constructing meaning, while maintaining a common discourse and common standards of scholarship?

Schapiro (1999) contends that in responding to these questions to achieve a democratic education for our times, our practice should be guided by four democratic principles as they have evolved over the past 25 years. These are the critical, feminist, and multicultural pedagogies as well as the notion of a participatory democracy (as achieved, for example, through participation of students and teachers in curriculum planning, in mutual evaluation, etc.).

\section{Focusing on Educational Goals}

In the remainder of this chapter I will focus on what faculty developers can do to promote a learning culture that embraces lifelong learning, broadly conceived. As we have seen, a philosophy of lifelong learning is based on an understanding that promoting those attitudes, skills, and knowledge that individuals need to function fully and responsibly in a democratic society, and to engage in continued learning throughout their lives, is an important goal of college and university teaching. Rather than focusing faculty development initiatives exclusively on how to facilitate student learning, the question that needs addressing first is that of what kind of learning to promote.

When faculty engage in learning about curricular and program goals and purposes, their learning is either communicative or emancipatory, or both (Kreber \& Cranton, 2000). Goals and purposes of teaching are the foundations of one's philosophy of teaching. A philosophy of teaching, generally 
speaking, provides a rationale for educational practice (Lawson, 1991; Ozmon \& Graver, 1990). Goodyear and Allchin (1998) suggest that "articulating an individual teaching philosophy provides the foundation by which to clarify goals, to guide behaviour, to seed scholarly dialogue on teaching, and to organise evaluation" (p. 103). Philosophies, therefore, are not something esoteric, abstract, and intangible that only those engaging in the formal study of education should be concerned with. Rather, educational philosophies are the roadmap to what we do as trainers or educators, and therefore are important for all instructors.

Whether we call it teaching philosophies, teaching perspectives, goals and values clarification, or conceptions of teaching and learning, the important point is that any professional practice is guided by certain goals, whether they are explicit or implicit. Helping others making their goals explicit and encouraging reflection on these, I would suggest, is an important aspect of faculty development, yet one that has received only marginal attention to date.

\section{Implications for Practice}

As for concrete ways by which faculty developers could promote attention to faculty beliefs about education and their roles as educators, discussion forums and reading circles seem particularly meaningful. As a start, faculty could also be encouraged to complete any of the inventories now available that identify one's beliefs about education. Examples include the "Philosophy of Adult Education Inventory" (Zinn, 1990), the "Teaching Perspectives Inventory" (Pratt \& Associates, 1998), or the "Approaches to Teaching Inventory" (Prosser \& Trigwell, 1996). Each of these instruments is easy to complete, requires little time for analysis, and is a powerful heuristic if the goal is to encourage reflection. They could be used in individual as well as group settings. Mezirow (1990), in his edited volume Fostering Critical Reflection in Adulthood, discusses many strategies faculty developers could use to further stimulate the reflective process. Among the strategies featured in the book are the use of critical incidents, metaphor analysis, repertory grids, and concept mapping. While the purpose in this chapter is not to discuss these strategies in detail (interested readers are referred to Mezirow's book) it may suffice to say that each of these strategies has as its goal to make one's underlying assumptions explicit and to trace their origins. They are, therefore, perfectly suited if the goal is to encourage emancipatory learning among faculty.

Once beliefs, assumptions, and values on teaching and on one's roles as educators have been identified, they would need to be compared to and assessed against a philosophy of lifelong learning. Faculty developers would play 
an important role in exploring together with faculty the meaning of lifelong learning and the implications of lifelong learning with respect to the design of programs, curricula, and courses so that these reflect course content and learning skills needed for lifelong learning. Such discussions should emphasize the importance of teaching knowledge and skills necessary for working life and the ability to learn how to learn. It seems equally important to encourage faculty to explore whether issues of equity and diversity' understanding of the local culture and differences between cultures-broadly conceived as including all areas of difference in gender, religion, disability, class, learning styles, race, age, ethnicity, culture, and sexual orientation-learning for ethics, citizenship, and democracy; environmental and health issues; interpersonal skills; and the ability to make informed and responsible value judgments are important skills and knowledge areas to consider in a system that commits itself to lifelong learning. Once faculty, through critical questioning and emancipatory learning, conclude that these are important skills and knowledge areas and that an important goal of college and university education is to teach these, how these issues could run as themes throughout their courses would be the next problem to tackle. Earlier I suggested that most of the studies currently done under the umbrella of the scholarship of teaching pay little attention to a critical interrogation of program and curricula goals. A meaningful project of involving faculty in the scholarship of teaching would be to explore together with them, perhaps in the form of an action research project, just how the goals associated with lifelong learning could be pursued across the curriculum.

\section{Conclusion}

While I believe that a philosophy of lifelong learning has the greatest potential to strive when it gains the support of the faculty, I also see a role of faculty developers in becoming agents of institutional change. As change agents, faculty developers would advocate a general learning climate on campus that is conducive to lifelong learning. Such a climate would value diversity (broadly conceived as including all differences in lifestyle and identity) and equity across all activities on campus. 


\section{REFERENCES}

Bandura, A. (Ed.). (1997). Self-efficacy in changing schools. Cambridge, MA: Cambridge University Press.

Boud, D. (1997). Providing for lifelong learning through work-based study. Challenges for policy and practice. Paper presented at the International Conference on Lifelong Learning, Guildford, Surrey, England.

Cambridge, B. L. (2000). The scholarship of teaching and learning: A national initiative. In M. Kaplan \& D. Lieberman (Eds.), To Improve the Academy: Vol. 18. Resources for faculty, instructional, and organizational development (pp. 55-68). Bolton, MA: Anker.

Candy, P. (1991). Self-direction for lifelong learning. San Francisco, CA: Jossey-Bass.

Carnegie Academy for the Scholarship of Teaching and Learning (CASTL). (n.d.). Available: htrp://www.middlesex.cc.ma.us/carnegie/

Cranton, P. A. (1994). Understanding and promoting transformative learning. San Francisco, CA: Jossey-Bass.

Cranton, P. A. (1996). Professional development as transformative learning. San Francisco, CA: Jossey-Bass.

Glassick, C., Huber, M., \& Maeroff, G. (1997). Scholarship assessed: Evaluation of the professoriate. Princeton, NJ: The Carnegie Foundation for the Advancement of Teaching.

Goodyear, G. E., \& Allchin, D. (1998). Statements of teaching philosophy. In M. Kaplan (Ed.), To improve the academy: Vol.17. Resources for faculty, instructional, and organizational development (pp. 103-122), Stillwater, OK: New Forums Press.

Habermas, J. (1971). Knowledge and human interests. Boston, MA: Beacon Press.

Habermas, J. (1981). Theorie des kommunikativen Handelns (Vols. 1 \& 2). Frankfurt, Germany: Suhrkamp.

Hutchings, P. (1999). 1999 Pew scholars institute. Menlo Park, CA: The Carnegie Foundation for the Advancement of Teaching.

Knapper, C., \& Cropley, A. (2000). Lifelong learning in higher education. London, England: Kogan Page.

Kreber, C. (2001). Designing a teaching portfolio based on a formal model of the scholarship of teaching. In D. Lieberman \& C. Wehlburg (Eds.), To improve the academy: Vol. 19. Resources for faculty, instructional, and organizational development (pp. 268-285). Bolton, MA: Anker. 
Kreber, C., \& Cranton, P. A. (2000). Exploring the scholarship of teaching. Journal of Higher Education, 71, 476-495.

Lawson, K. H. (1991). Philosophical foundations. In P. Jarvis \& J. M. Peters (Eds.), Adult education (pp. 282-301). San Francisco, CA: Jossey-Bass.

Lengrand, P. (1986). Areas of learning basic to lifelong education. Oxford, England: Pergamon.

Little, T. C. (1983). The institutional context for experiential learning. In T. C. Little (Ed.), Making sponsored experiential learning standard practice. San Francisco, CA: Jossey-Bass.

Marsick, V. (1990). Action learning and reflection in the workplace. In J. Mezirow (Ed.), Fostering critical reflection in adulthood (pp. 23-47). San Francisco: JosseyBass.

Mezirow, J. (Ed.). (1990). Fostering critical reflection in adulthood. San Francisco, CA: Jossey-Bass.

Mezirow, J. (1991). Transformative dimensions of adult learning. San Francisco, CA: Jossey-Bass.

Mezirow, J. (2001). Learning as transformation. San Francisco, CA: Jossey-Bass.

Ozmon, H., \& Graver, S. (1990). Philosophical foundations of education (4th ed.). Toronto, Canada: Merrill Publishing Company.

Pratt, D. D., \& Associates. (1998). Five perspectives on teaching in adult and higher education. Malabar, FL: Krieger.

Prosser, M., \& Trigwell, K. (1996). Congruence between intention and strategy in science teachers; approach to teaching. Higher Education, 32, 77-87.

Schapiro, S. A. (1999). Higher education for democracy. New York, NY: Peter Lang.

Zinn, L. (1990). Identifying your philosophical orientation. In M. W. Galbraith (Ed.), Adult learning methods: A guide to effective instruction (pp. 60-74). Malabar, FL: Krieger.

\section{Note}

The ideas expressed in this chapter were developed as part of a larger study funded by the Social Sciences and Humanities Research Council of Canada. 
Contact:

Carolin Kreber

Associate Professor of Adult and Higher Education

Department of Educational Policy Studies

University of Alberta

Edmonton, Alberta T6G 2G5 Canada

Voice (780) 4927623

Fax (780) 4922024

Email carolin.kreber@ualberta.ca

Carolin Kreber has been a faculty member in the Adult and Higher Education Program of the Department of Educational Policy Studies at the University of Alberta since 1997. She reaches undergraduate and graduate courses on adult learning and development, instructional design, and current issues in postsecondary education. From 1993 to 1997, she worked as an educational development consultant at the Instructional Development Office at Brock University in Southern Ontario. Her present research focuses on faculty roles and responsibilities, higher education and lifelong learning, diversity and equity, and teaching and learning in higher education. 